\title{
Corrigendum
}

\section{Corrigendum to "Projected Changes in Precipitation Extremes over Shaanxi Province, China, in the 21st Century"}

\author{
Ling Li $\mathbb{D},{ }^{1}$ Ziniu Xiao, ${ }^{2}$ Shuxiang Luo, ${ }^{1}$ and Aili Yang $\mathbb{D}^{3}$ \\ ${ }^{1}$ Beijing Building Technology Development Co., Ltd., Beijing 100069, China \\ ${ }^{2}$ State Key Laboratory of Numerical Modeling for Atmospheric Sciences and Geophysical Fluid Dynamics (LASG), \\ Institute of Atmospheric Physics, Chinese Academy of Sciences, Beijing 100029, China \\ ${ }^{3}$ Xiamen University of Technology, Xiamen 361024, China \\ Correspondence should be addressed to Ling Li; yamdestiny@163.com
}

Received 11 December 2020; Accepted 11 December 2020; Published 21 December 2020

Copyright @ 2020 Ling Li et al. This is an open access article distributed under the Creative Commons Attribution License, which permits unrestricted use, distribution, and reproduction in any medium, provided the original work is properly cited.

In the article titled "Projected Changes in Precipitation Extremes over Shaanxi Province, China, in the 21st Century" [1], 2 additional references should have been cited included in the text below as references 43 [2] and 44 [3]. Accordingly, the sentence referring to the model output data in Section 2.2, Model and Data, should read as follows.

The model output data over Shaanxi province obtained by the Xuejie Gao research group were used for the study, and more information about the model and simulation could be found in studies by Gao et al. [43, 44].

The Acknowledgments section should also be updated as follows.

The authors are grateful to the Xuejie Gao research group from the LASG in the Institute of Atmospheric Physics, the Chinese Academy of Sciences, for providing model output data of RegCM4 used in this study. This research was funded by the 2018 Open Research Program of LASG in the Institute of Atmospheric Physics, the Chinese Academy of Sciences, and Research Program of Beijing Construction Engineering Group (SGGA1427000000002016002).

\section{References}

[1] L. Li, Z. Xiao, S. Luo, and A. Yang, "Projected changes in precipitation Extremes over Shaanxi province, China, in the 21st century," Advances in Meteorology, vol. 2020, Article ID 1808404, 13 pages, 2020.

[2] X. Gao, Y. Shi, Z. Han et al., "Performance of RegCM4 over major river basins in China," Advances in Atmospheric Sciences, vol. 34, no. 4, pp. 441-455, 2017.
[3] X.-J. Gao, J. Wu, Y. Shi et al., "Future changes in thermal comfort conditions over China based on multi-RegCM4 simulations," Atmospheric and Oceanic Science Letters, vol. 11, no. 4, pp. 291-299, 2018. 